Research Article

\title{
Blasting Energy Analysis of the Different Cutting Methods
}

\author{
Ke Man $\mathbb{D}^{1,2}$ Xiaoli Liu $\left(D,{ }^{3}\right.$ Ju Wang, ${ }^{1,2}$ and Xiyong Wang ${ }^{1,2}$ \\ ${ }^{1}$ Division of Environment Engineering, Beijing Research Institute of Uranium Geology, Beijing 100029, China \\ ${ }^{2}$ Key Laboratory of China National Nuclear Corporation on High Level Radioactive Waste Geological Disposal, \\ Beijing 100029, China \\ ${ }^{3}$ State Key Laboratory of Hydroscience and Hydraulic Engineering, Tsinghua University, Beijing 100084, China \\ Correspondence should be addressed to Xiaoli Liu; xiaoli.liu@tsinghua.edu.cn
}

Received 3 September 2018; Revised 31 October 2018; Accepted 2 December 2018; Published 16 December 2018

Academic Editor: Shuaishuai Sun

Copyright (C) 2018 Ke Man et al. This is an open access article distributed under the Creative Commons Attribution License, which permits unrestricted use, distribution, and reproduction in any medium, provided the original work is properly cited.

\begin{abstract}
Based on the smooth blasting method, the blasting parameters of the Beishan exploration tunnel have been designed. According to the principle of blasting parameters design, three kinds of cutting methods have been laid out, which are straight parallel hole cutting, single-wedge cutting, and double-wedge cutting. The other parameters such as the borehole number, the detonator segment, and the charge amount of each hole are also designed. Then, the blasting tests under different cutting methods were carried out in the field. The results show that all the three cutting methods can achieve good utilization ratio of blasting holes. The blasting effect of straight parallel hole cutting is good. The rock slag size of single-wedge and double-wedge cutting is uniform, which is beneficial to slag extraction. Moreover, the blasting vibration velocity and blasting energy have been analyzed. It is found that the energy distribution of single-wedge and double-wedge cutting is more uniform, mainly concentrated in the highfrequency part, while the energy of straight parallel hole cutting is more concentrated in the low-frequency part. Among many factors affecting blasting vibration velocity, besides the explosive quantity, it would also be easily influenced by the cutting way. It should be noticed that the blasting method includes numerous blasting parameters, which interact with each other. Those blasting parameters obtained were just limited to the cutting method, and the result and the theoretical knowledge could be applied to the blasting and excavation of the deep geoengineering and the HLW geo-disposal.
\end{abstract}

\section{Introduction}

As the damage of the surrounding rock can be effectively controlled by the smooth blasting method, the smooth blasting technology has been more and more applied to engineering. It is very important to select the blasting parameters during the blasting design process.

A lot of research based on different starting points and diverse blasting mechanism has been analyzed by scholars at home and abroad [1-6]. Among them, the choice of the cutting method has a great influence on the construction efficiency and slag formation of smooth blasting. According to the blasting theory, Shan et al. $[7,8]$ put forward the quasiparallel cutting method. The main cutting hole is slightly inclined, and the distance between the bottom holes is large, whereas the secondary cutting hole is perpendicular to the free surface. This cutting method can eliminate the perforation phenomenon, with simple form, large cavity, high efficiency, and low cost. Yang et al. [9] have found that, with the increase of blasting hole depth, the rock clamping effect was much more serious and the throwing effect was worse. In view of this characteristic, the compound wedgeshaped cutting blasting technology was put forward, in which the straight hole and the oblique hole were intersected. Combined with numerical simulation results using LS-DYNA, the propagation law of stress wave in the cavity was revealed and the formation process of the cavity at the bottom of the borehole was reproduced [10].

Aiming at the low blasting efficiency of roadway in an iron mine, the cutting method is the main factor that restricts its driving efficiency, which is considered by Lei et al. [11]. By comparing the three cutting methods of doublewedge cutting, single screw cutting, and nine holes cutting, it is concluded that the excavation efficiency can be improved by the single screw cutting, by which the economic benefits in actual construction can also be obtained. For the poor 
effect of smooth blasting in the hard rock, the medium-long hole blasting test was carried out in the hard rock roadway of Shuangyang Coal Mine by Chen et al. [12]. According to the different cutting effects, it has been drawn that the compound barrel cutting is completely suitable for medium-hole and deep-hole blasting and this cutting method has the advantage of a high rate on the hole utilization.

As a technical research facility for the geological disposal of high-level radioactive waste in China, BET (Beishan exploration tunnel) facility has carried out various construction skills related to the excavation engineering, such as blasting test, rock deformation monitoring, EDZ monitoring, advanced detection, grouting test, and so on. The main difference between the BET project and the other underground projects is that it demands the EDZ value as small as possible.

The underground repository facilities need to be safe for thousands of years. It means that the nuclides must be ensured of not migrating from the surrounding rock to the nature. In view of the actual conditions of the BET, the blasting parameters of the drilling and blasting test are designed and the different cutting methods are carried out. The blasting effect, the blasting vibration velocity, and the blasting energy are analyzed and discussed.

\section{Engineering Background}

BET facility is located in Gobi, Gansu Province, about $80 \mathrm{~km}$ northeast of YuMen City. The main project of BET facilities includes tunnel door, inclined shaft, alley, water storehouse, test chamber, shelter, ventilation hole, as well as the water supply, power supply, and ventilation system.

The surrounding rock of the project is mainly granite, and its static compressive strength is $150 \mathrm{MPa}$ and tensile strength is $13 \mathrm{MPa}$. Its stress-strain curve is shown in Figure 1 . And, the static compressive strength is obtained by the MTS system, while the tensile strength is calculated from the indirect Brazilian testing, which are all based on the ISRMsuggested method. The fracture (F18) moved toward $60^{\circ}$, which tended to be NW or SE, with a dip angle of $75 \sim 85^{\circ}$.

The tectonic fracture zone is fragmented and fractured, especially in the center of the tectonic belt. The blasting parameters are quantified by theoretical calculation and semiempirical analysis, respectively. The longitudinal wave velocity of the rock is $3500 \mathrm{~m} / \mathrm{s}$.

In order to study the rock blasting effect and quantify the surrounding rock vibration degree, the blasting vibration monitoring test is carried out. The schematic of all testing in BET and the monitoring chamber for the blasting test is shown in Figure 2.

It is located in the monitoring chamber at the bottom site of the inclined shaft, which is close to the test chamber for drilling and blasting. And, the blasting vibration monitoring is located in front of the drilling and blasting face.

\section{Blasting Parameters Design}

The main purpose of the smooth blasting technology is the interconnection of the surrounding hole, and the tunnel

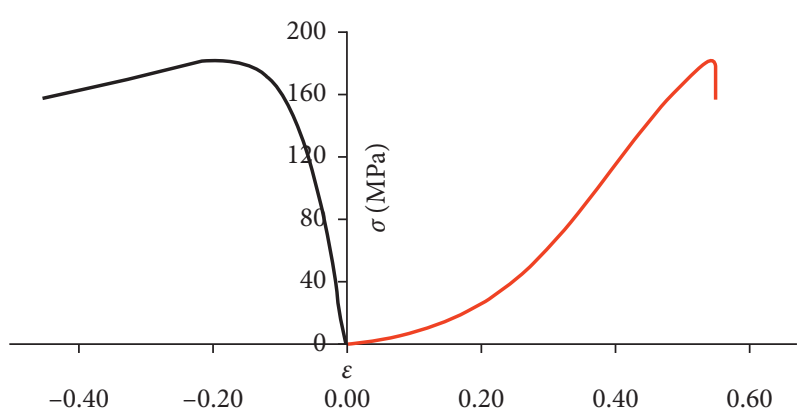

FIgURE 1: Relationship between the stress and the strain of the granite.

surface could be even and smooth when a fine half-hole ratio of the blasting hole on the rock surface is achieved. Simultaneously, the damage to the surrounding rock is small. In order to achieve this purpose, a suitable blasting parameter should be designed combined with the rock condition, construction equipment, explosive series, engineer level, and so on.

No. 2 rock emulsion explosive is selected here, which is widely used in civil engineering. And, it has strong adaptability and water resistance. The main performances are as follows: the diameter of the explosive is $32 \mathrm{~mm}$, the density is $0.95 \sim 1.30 \mathrm{~g} /$ $\mathrm{cm}^{3}$, the detonation velocity is above $3500 \mathrm{~m} / \mathrm{s}$, the intensity is upon $12 \mathrm{~mm}$, the detonation force is greater than $320 \mathrm{ml}$, the martyrdom distance is more than $8 \mathrm{~mm}$, the explosion heat is $4015333 \mathrm{~J} / \mathrm{kg}$, the detonation temperature is $2654^{\circ} \mathrm{C}$, and the detonation pressure is $395000 \mathrm{~N} / \mathrm{cm}^{2}$. The weight of each volume of explosive is $300 \mathrm{~g}$. The emulsion explosive is used in the surrounding blasting holes to be cut into several segments on average, using air spacing with uncoupled charge.

In order to study the damage degree and blasting vibration effect of different blasting parameters on rock mass, each footage of the blasting cycle keeps the same, which is $2 \mathrm{~m}$.

A millisecond delay with a nonelectric detonator is used to detonate, and the cutting holes adopt continuous coupling charge, the auxiliary holes and the bottom holes adopt continuous noncoupling charge, and the surrounding holes adopt the air interval with noncoupling charge to bind the interval of the explosive to the detonator and then attach the bamboo sheet to the bottom of the hole.

The blockage length of the blasting hole is as follows: corresponding length of the surrounding hole, auxiliary hole is not less than $200 \mathrm{~mm}$, and the cutting hole is not less than $400 \mathrm{~mm}$.

The cutting method is an important factor influencing the quality of smooth blasting. Usually, the blasting begins with cutting at the central part, then the auxiliary hole blasting in turn, and all the surrounding holes blasting at the same time, finally the bottom holes blasting. Among them, the smooth blasting effect is directly determined by the cutting effect. As the subsequent auxiliary hole and the surrounding hole blasting are limited by blasting effect of the cut hole, the cut cavity size, and the space distribution of the cut cavity.

The main purpose of cutting is to produce more effective blasting free face. It should be noticed that the cut holes spacing needs to be uniform and they are all in a same ring 


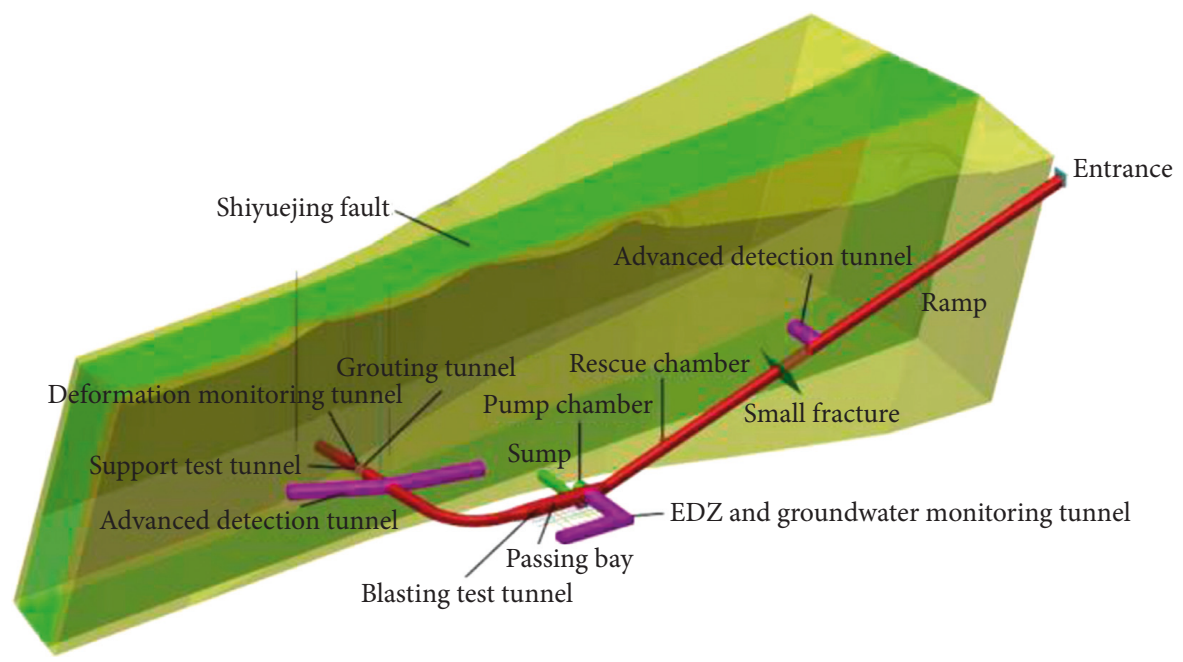

(a)

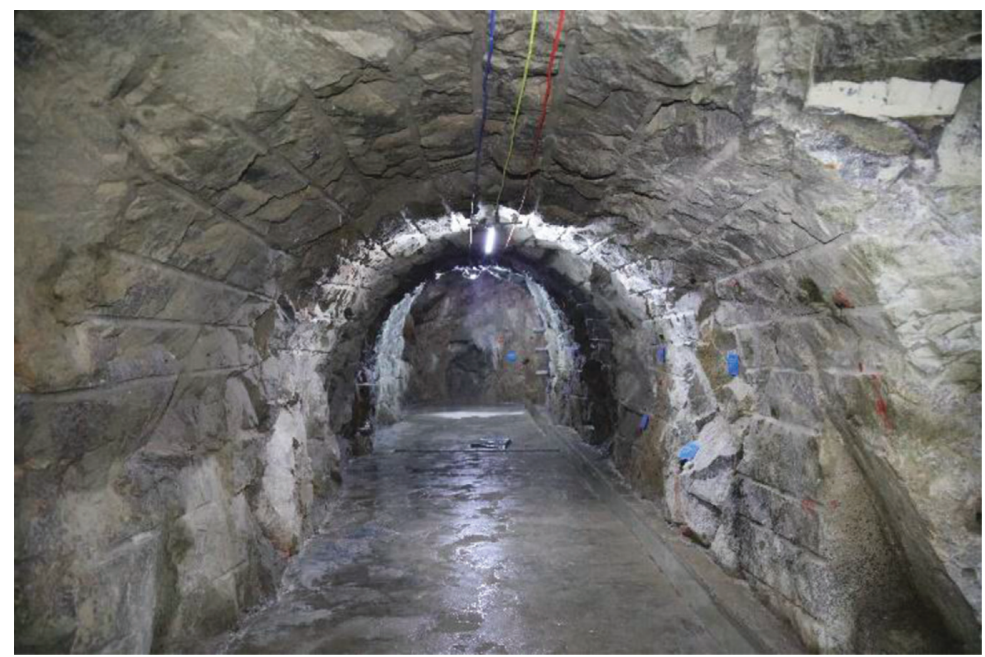

(b)

Figure 2: Site for blasting test.

range, then they can be initiated simultaneously with the same detonator section, and the auxiliary hole close to the cutting hole can achieve a more reasonable blasting interval. As the smooth blasting is directly affected by the cutting layout, the calculation, design, and analysis of the cutting method are described here.

\section{Cutting Method Design}

According to the principle of blasting, combined with the geological and test conditions, three kinds of cutting schemes are arranged here, which are straight parallel cutting, single-wedge cutting, and double-wedge cutting, separately. The layout of the cutting methods is shown in Figures 3-5, and the cutting parameters are shown in Tables 1-3.

The design principles are as follows: firstly, only the cutting method is changed while the other blasting parameters remain unchanged. Secondly, the number of boreholes and the total charge of each cutting method are kept as consistent as possible, but the space distribution of the cutting holes is different. Moreover, the distribution area of each cutting in the face is roughly the same. Finally, the number of explosive consumables used in different cutting methods is consistent. Only on this basis, the merits and demerits of each cutting method can be comparative and the results can be scientifically credible.

For the cutting design of this project, the cutting range is in the middle and lower part of the tunnel face and the number and depth of the cutting holes are basically consistent. In particular, the explosive loading of the cutting hole is consistent, and the explosive consumption is consistent.

4.1. Straight Parallel Hole Cutting. The straight parallel hole cutting design includes seven holes, in which six peripheral holes lie at equidistant around the center hole, and the angle between adjacent holes is $60^{\circ}$.

The six peripheral holes evenly distributed are charged, and the central hole is an empty hole with no charge. The 


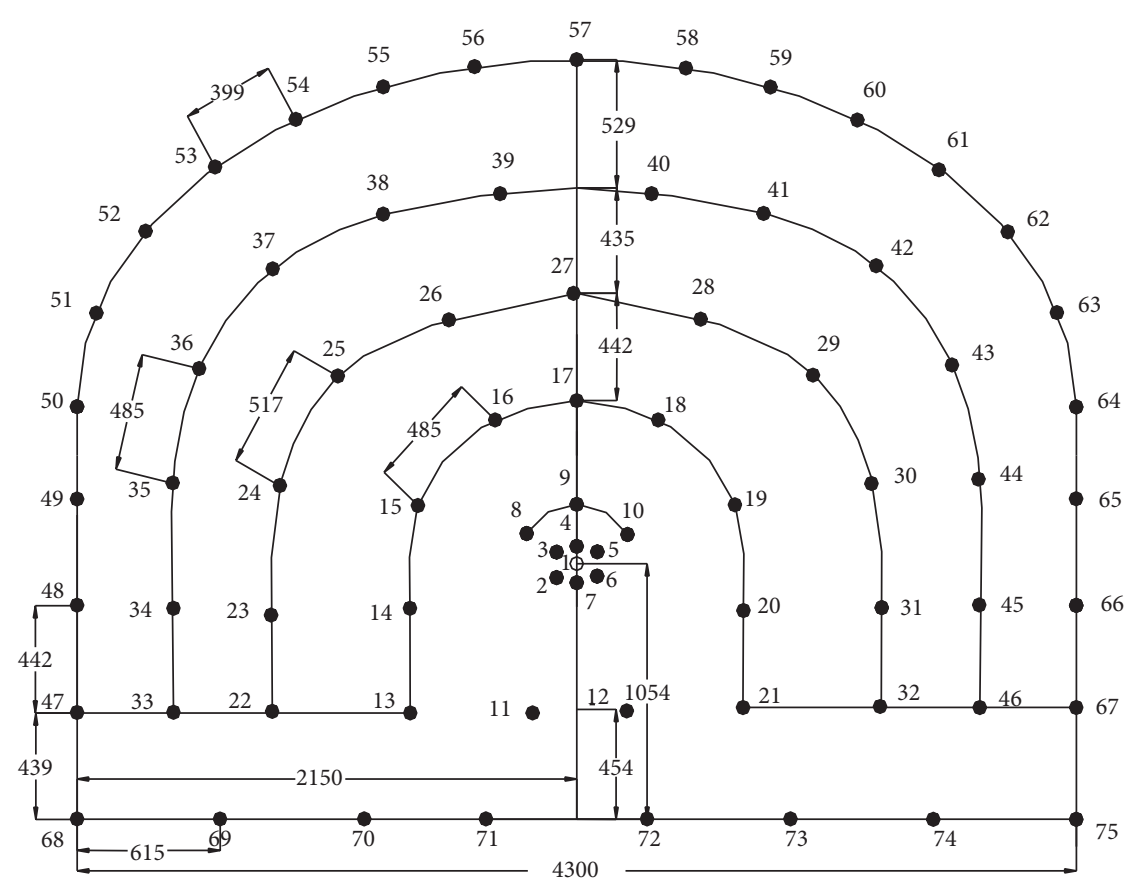

(a)

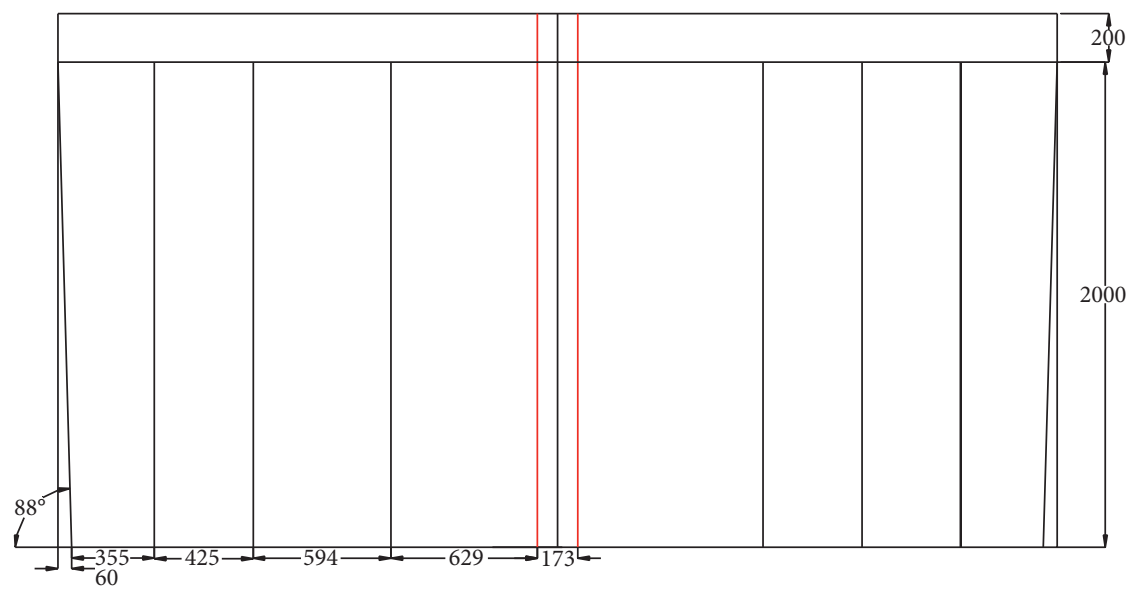

(b)

Figure 3: Blasting scheme of parallel hole cutting (unit: $\mathrm{mm}$ ).

detonator sections of the six peripheral holes are the same, and they are the first-order detonator, ensuring that they can be detonated simultaneously. The free volume of the central hole drilled in advance can be used fully, which is easier to release the energy of the surrounding peripheral hole and to form the cutting cavity.

The auxiliary holes are divided into five circles. The first auxiliary hole is No. 8, No. 9, and No. 10 near the cutting hole, which is located above the cutting hole. The purpose is to use the cavity of the cutting hole in time, to press down the rock and make full use of the cutting effect. The second auxiliary holes, i.e., No. 11 and No. 12, are arranged at the lower part of the cut hole. It is to explode the rock upward by using the formed cut cavity. No. 13-No. 21 are the third auxiliary hole, No. 22-No. 32 are the fourth auxiliary hole, and No. 33-No. 46 are the fifth auxiliary hole. No. 47-No. 67 holes are peripheral hole, and No. 69-No. 74 holes are bottom hole, while No. 68 and No. 75 holes are bottom corner hole. The distance between peripheral holes is $399 \mathrm{~mm}$. The depth of each cutting hole is about $10 \%$ deeper than that of other drilled holes, that is, the hole depth is $2.2 \mathrm{~m}$.

According to the principle that the charge in the inner hole is large and it is gradually reduced in the outer hole, the charge in each hole is arranged. It should be noted that as the bottom hole and the bottom corner hole are subjected to greater clamping pressure, the amount of explosive needed to increase, especially the bottom corner hole is subjected to a much more severe clamping.

At the same time, the order of the blasting sequence and detonator section initiate in turn from inside to outside, making the hole detonate under a certain time interval. 


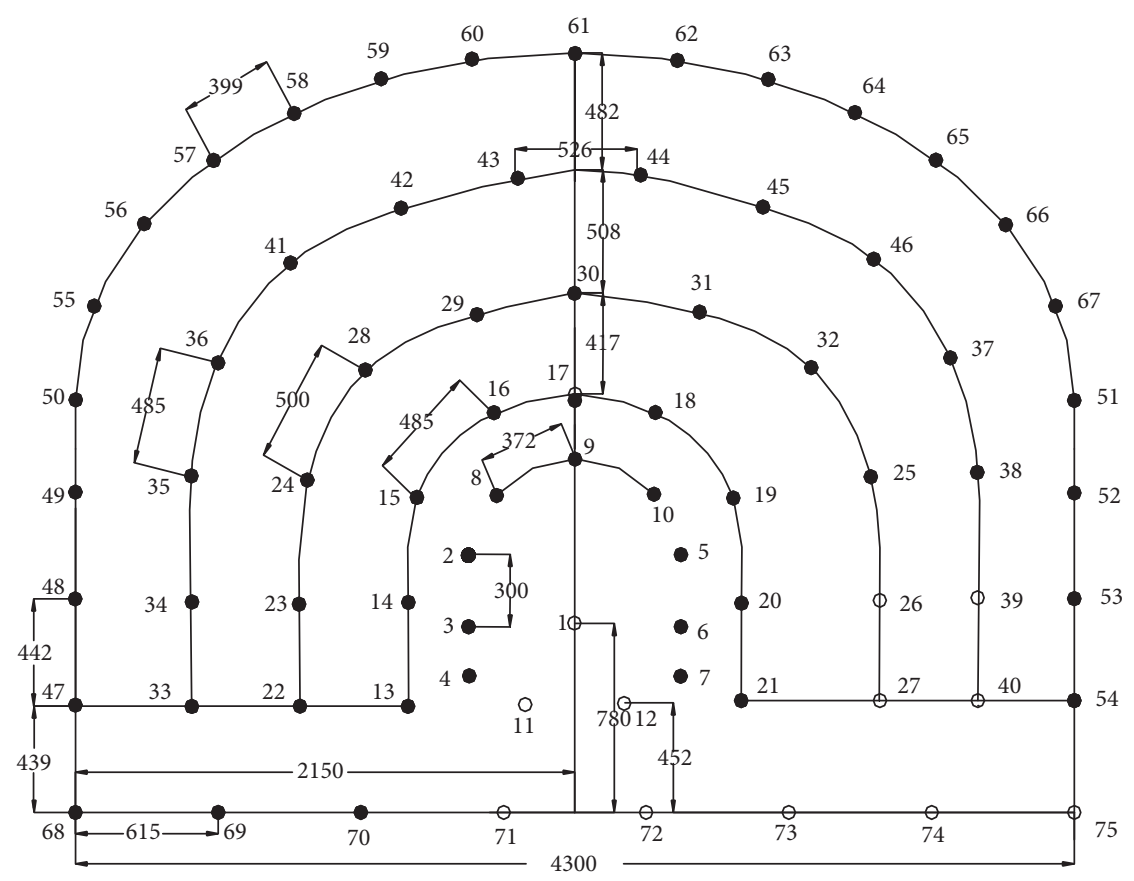

(a)

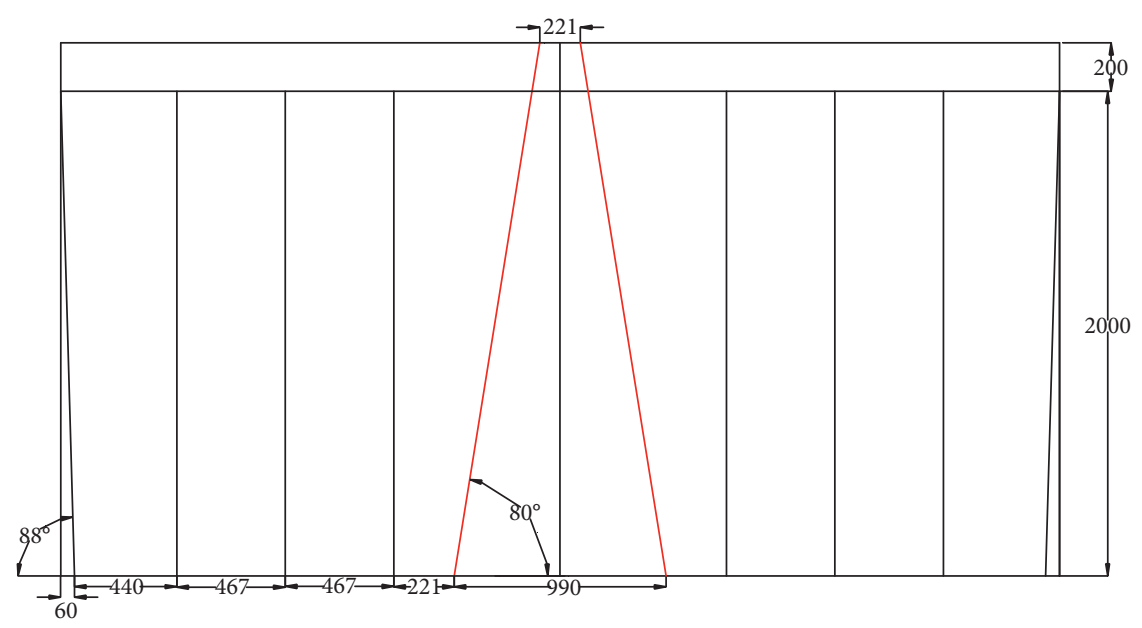

(b)

Figure 4: Blasting scheme of single-wedge hole cutting (unit: $\mathrm{mm}$ ).

It should also be explained that the same round of the hole must be detonated at the same time to ensure a good smooth blasting effect.

The design of the blast hole is shown in Figure 3, and the blasting parameters are shown in Table 1.

4.2. Single-Wedge Cutting. The design of single-wedge cutting includes seven holes, which are divided into one central hole and six cutting holes. Around the center hole, six wedge-shaped cutting holes are arranged vertically in two rows with three holes in each row. The central hole is a straight hole drilled perpendicular to the free face. The six wedge-shaped cutting holes are oblique holes with an angle of $80^{\circ}$ with the free face, and the drilling angles are all toward the central hole.
Six wedge-shaped holes are charged, and the central hole is also charged. However, the explosive in the central hole is less than that in each wedge hole. The detonator sections of the six wedge-shaped holes are the same, which are all the first-order detonator, ensuring that all the wedge-shaped holes can be detonated simultaneously. The detonator segment in the central hole uses the third-order detonator, which means that it initiates a little later than the wedgeshaped cutting holes. It can make use of the preblasting volume of wedge-shaped cutting holes and further superimpose the blasting of the central hole, which is beneficial to remove the residual rock at the bottom of the cutting cavity and is easier to form the cutting cavity.

The auxiliary holes are also divided into five circles. No. 8, No. 9 , and No. 10 holes near the cutting hole are the first 


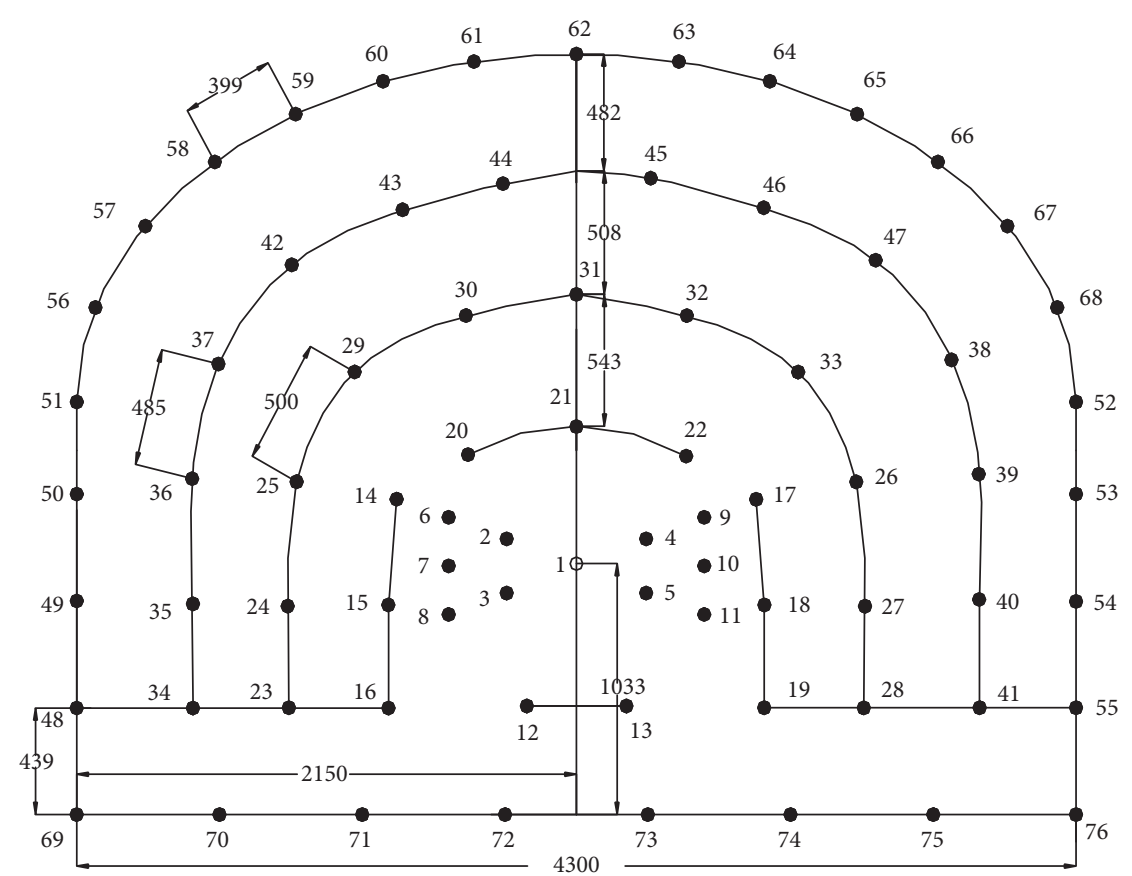

(a)

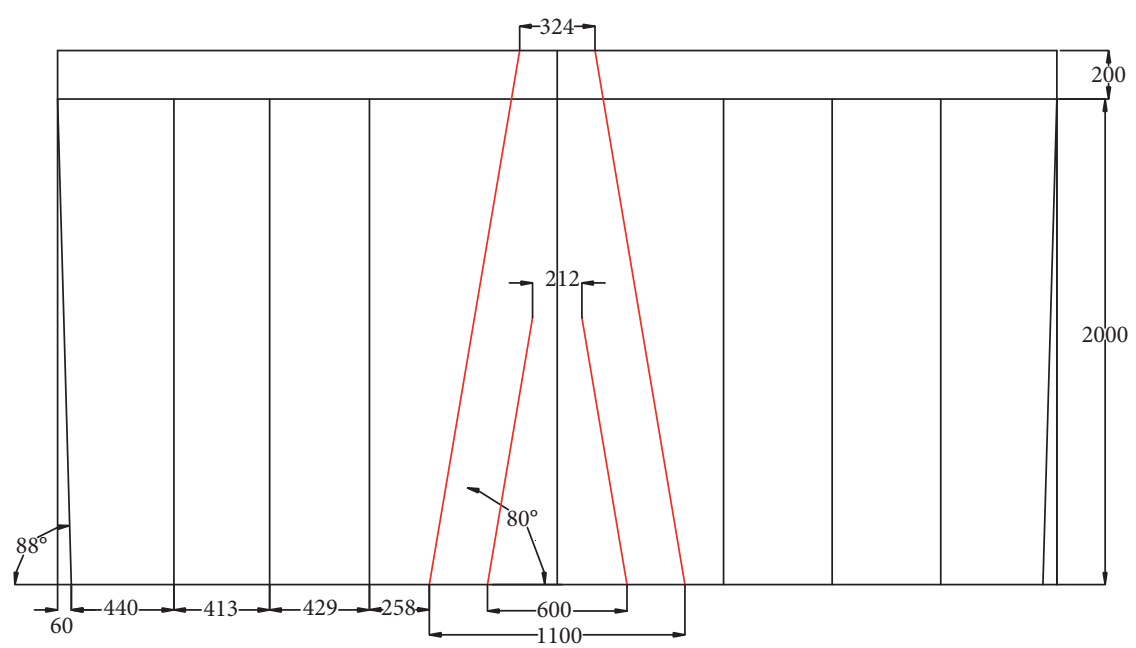

(b)

FIGURE 5: Blasting scheme of duplex wedge hole cutting (unit: mm).

TABLE 1: Blasting parameters table for the scheme.

\begin{tabular}{|c|c|c|c|c|c|}
\hline \multirow{2}{*}{ Hole name } & \multirow{2}{*}{ Hole no. } & \multirow{2}{*}{ Number of holes } & \multicolumn{2}{|c|}{ Charge quantity } & \multirow{2}{*}{ Detonator order } \\
\hline & & & Explosive volume per each hole & Total weight $(\mathrm{kg})$ & \\
\hline Empty hole & 1 & 1 & 0 & 0.0 & \\
\hline Cutting hole & $2-7$ & 6 & 3.5 & 6.3 & 1 \\
\hline Auxiliary hole & $8-10$ & 3 & 2.5 & 2.3 & 3 \\
\hline Auxiliary hole & $11-12$ & 2 & 2.5 & 1.5 & 5 \\
\hline Auxiliary hole & $13-21$ & 9 & 2.5 & 6.5 & 7 \\
\hline Auxiliary hole & $22-32$ & 11 & 2.5 & 8.3 & 8 \\
\hline Auxiliary hole & $33-46$ & 14 & 2.0 & 8.4 & 9 \\
\hline Peripheral hole & $47-67$ & 21 & 1.5 & 9.5 & 15 \\
\hline Bottom hole & $69-74$ & 6 & 3.0 & 5.4 & 15 \\
\hline Bottom hole & 68,75 & 2 & 3.0 & 1.8 & 19 \\
\hline Total & & 75 & & 50.3 & \\
\hline
\end{tabular}


TABLE 2: Blasting parameters of single-wedge hole cutting.

\begin{tabular}{|c|c|c|c|c|c|}
\hline \multirow{2}{*}{ Hole name } & \multirow{2}{*}{ Hole no. } & \multirow{2}{*}{ Number of holes } & \multicolumn{2}{|c|}{ Charge quantity } & \multirow{2}{*}{ Detonator order } \\
\hline & & & Explosive volume per each hole & Total weight $(\mathrm{kg})$ & \\
\hline Central hole & 1 & 1 & 0.5 & 0.15 & 3 \\
\hline Cutting hole & $2-7$ & 6 & 3.5 & 6.30 & 1 \\
\hline Auxiliary hole & $8-10$ & 3 & 2.5 & 2.30 & 5 \\
\hline Auxiliary hole & $11-12$ & 2 & 2.5 & 1.50 & 5 \\
\hline Auxiliary hole & $13-21$ & 9 & 2.5 & 6.75 & 7 \\
\hline Auxiliary hole & $22-32$ & 11 & 2.5 & 8.25 & 8 \\
\hline Auxiliary hole & $33-46$ & 14 & 2.0 & 8.40 & 9 \\
\hline Peripheral hole & $47-67$ & 21 & 1.5 & 9.45 & 15 \\
\hline Bottom hole & $69-74$ & 6 & 3.0 & 5.40 & 15 \\
\hline Bottom hole & 68,75 & 2 & 3.0 & 1.80 & 19 \\
\hline Total & & 75 & & 50.3 & \\
\hline
\end{tabular}

TABLE 3: Blasting parameters after optimization.

\begin{tabular}{|c|c|c|c|c|c|}
\hline \multirow{2}{*}{ Hole name } & \multirow{2}{*}{ Hole no. } & \multirow{2}{*}{ Number of holes } & \multicolumn{2}{|c|}{ Charge quantity } & \multirow{2}{*}{ Detonator order } \\
\hline & & & Explosive volume per each hole & Total weight $(\mathrm{kg})$ & \\
\hline Empty hole & 1 & 1 & 0 & 0.0 & \\
\hline First cutting hole & $2-5$ & 4 & 1 & 1.2 & 1 \\
\hline Second cutting hole & $6-11$ & 6 & 3.5 & 6.3 & 3 \\
\hline Auxiliary hole & $12-13$ & 2 & 2.5 & 1.5 & 5 \\
\hline Auxiliary hole & $14-22$ & 9 & 3 & 7.65 & 7 \\
\hline Auxiliary hole & $23-33$ & 11 & 2.5 & 8.25 & 8 \\
\hline Auxiliary hole & $34-47$ & 14 & 2 & 8.4 & 9 \\
\hline Peripheral hole & $48-68$ & 21 & 1.5 & 9.45 & 15 \\
\hline Bottom hole & $70-75$ & 6 & 3 & 5.4 & 15 \\
\hline Bottom hole & 69,76 & 2 & 3 & 1.8 & 19 \\
\hline Total & & 76 & & 49.95 & \\
\hline
\end{tabular}

auxiliary holes, which are located above the cutting hole. No. 11 and No. 12 holes are arranged at the lower part of the cutting hole, which are the second-level auxiliary holes. The difference between the straight parallel hole cutting and the single-wedge cutting is that the detonator segments used in the first-level and second-level auxiliary holes are the same, both of which are the fifth-order segment. This is to ensure that the cutting cavity can be better shaped, simultaneously considering that the detonator segments of other holes should be consistent with the straight parallel hole cutting design as far as possible. Because the influence range of single-wedge cutting is larger than that of straight parallel hole cutting, the distance of the minimum resistance line of the first-level and second-level auxiliary holes away from the cutting cavity is basically equal, and the same order detonator can be detonated at the same time.

As with straight parallel hole cutting, No. 13-No. 21 holes are the third auxiliary hole, No. 22-No. 32 holes are the fourth auxiliary hole, and No. 33-No. 46 holes are the fifth auxiliary hole. No. 47-No. 67 holes are peripheral hole, No. 69-No. 74 holes are bottom hole, and No. 68 and No. 75 holes are bottom corner hole. The distance between peripheral holes is also $399 \mathrm{~mm}$.

The depth of each cutting hole is deeper than that of other holes. The bottom of the cutting hole should be kept on the same plane behind the free surface. The projection length vertical to the free face of the cutting hole is $2.2 \mathrm{~m}$, which is about $10 \%$ deeper than other holes. At the same time, the distance between the two rows of cutting holes at the bottom is $221 \mathrm{~mm}$, keeping a certain distance, which is more conducive to the formation of the cutting cavity. Meanwhile, it can also prevent the bottom of the borehole from intersecting because of a small angle with the free surface.

According to the principle that the charge in the inner hole is large and it is gradually reduced in the outer hole, the charge in each hole is arranged. It should be noted that, as the bottom hole and the bottom corner hole are subjected to greater clamping pressure, the amount of explosive needed to increase especially the bottom corner hole is subjected to a much more severe clamping.

At the same time, the order of the blasting sequence and detonator section initiate in turn from inside to outside, making the hole detonating under a certain time interval. It should also be explained that the same round of the hole must be detonated at the same time to ensure a good smooth blasting effect.

The design of the blast hole is shown in Figure 4, and the blasting parameters are shown in Table 2.

4.3. Double-Wedge Cutting. The double-wedge cutting design includes eleven holes, which are divided into one central hole, four first-level cutting holes, and six second-level cutting holes. Around the central hole, ten wedge-shaped cutting holes are arranged in four vertical rows, while each side has two rows. The first row has two first-level cutting 
holes, and the second row has three second-level cutting holes. The central hole is a straight hole drilled perpendicular to the free surface. The ten wedge-shaped cutting holes are oblique holes with an angle of $80^{\circ}$ with the free surface, and the drilling angles are all toward the central hole. The horizontal distance between the first-level cutting hole and the second-level cutting hole is $250 \mathrm{~mm}$.

The ten wedge-shaped cutting holes are charged, and the central hole is filled with no explosive. The first-order detonator is used for the first-level cutting hole, ensuring that the first-level cutting holes can be detonated simultaneously. The third-order detonator is used for the second-level cutting hole, of which the initiation is slightly later than the first-level cutting hole. The graded blasting has been applied here, using the constant stacking of the wedge-shaped cutting hole blasting, to achieve a good cutting effect. At the same time, the free volume formed in advance by the central hole makes the cutting more effective, and it can also clear the rock convex at the bottom of the wedge-shaped cutting cavity, which is beneficial to form the cutting cavity.

The auxiliary holes are divided into four circles. The first level is the No. 12 and No. 13 holes, which are close to the cutting hole and are located below. No. 14-No. 22 holes are the second-level auxiliary hole. Among them, No. 20, No. 21, and No. 22 holes above the cutting hole basically have the same distance as No. 14-No. 19 holes away from the cutting cavity, so they can be designed as a same-level auxiliary hole, that is, the second-level auxiliary hole.

No. 23-No. 33 holes are the third-level auxiliary hole, and the No. 34-No. 47 holes are the fourth-level auxiliary hole. No. 48-No. 68 holes are peripheral hole, No. 70-No. 75 holes are the bottom hole, No. 69 and No. 76 holes are bottom corner hole. The distance between peripheral holes is the same as that of the other two design cutting methods.

The bottom of the first-level cutting holes should be kept on the same plane behind the free surface, and the projection length perpendicular to the free surface is $1 \mathrm{~m}$. It is the same for the second-level cutting holes, while the projection length is $2.2 \mathrm{~m}$, which is about $10 \%$ deeper than other holes. The distance between the first-level cutting hole at the bottom is $212 \mathrm{~mm}$, which keeps a certain distance. The distance between the second-level cutting hole at the bottom is $324 \mathrm{~mm}$, which is more conducive to the formation of the blasting cavity and prevents the hole from intersecting at the bottom.

According to the principle that the charge in the inner hole is large and it is gradually reduced in the outer hole, the charge in each hole is arranged. It should be noted that, as the bottom hole and the bottom corner hole are subjected to greater clamping pressure, the amount of explosive needed to increase, especially the bottom corner hole, is subjected to a much more severe clamping.

At the same time, the order of blasting sequence and detonator section initiate in turn from inside to outside, making the hole detonating under a certain time interval. It should also be explained that the same round of the hole must be detonated at the same time to ensure a good smooth blasting effect.
The design of the blast hole is shown in Figure 5, and the blasting parameters are shown in Table 3.

According to the order of detonation in sequence, the blasting is detonated in the order of "cutting hole-auxiliary hole-peripheral hole-bottom hole-bottom corner hole." The detonator sections designed by each cutting method are all of the orders $8 \mathrm{~ms}$, and the detonator orders corresponding to each series holes are also consistent, so that the test results are more comparable. The cutting hole is blocked up to $600 \mathrm{~mm}$, and the other stemming is $300 \mathrm{~mm}$ long.

\section{Blasting Tests Using the Designed Cutting Method}

The blasting effects of cutting methods designed above are tested by means of an in-site test here, while only the cutting method is changed and the other parameters are kept the same.

Meanwhile, the preparation and the arrangement and instrumentation of the blasting test are shown in Figures 6-8, respectively.

5.1. Blasting Using the Straight Parallel Hole Cutting. For the straight parallel hole cutting, the central hole is not charged and the space between the cutting holes is $100 \mathrm{~mm}$. The cutting holes are continuously charged, while the peripheral holes are spaced charged. Before each blasting, the waistline and the center line of the face should be fixed and the hole distribution should be arranged, and then drilling, charging, and blasting. The blasting effect is shown in Figure 9.

The tunneling footage is $1.9 \mathrm{~m}$, and the half-hole ratio of peripheral hole is higher, reaching up to $80 \%$. The smooth blasting effect is better. However, the throwing distance of the rock slag is relatively close, and different sizes of slag are distributed in front of the free face.

5.2. Blasting Using the Single-Wedge Cutting. The central hole of the single-wedge cutting is a straight hole, and the distance between two adjacent cutting holes is $300 \mathrm{~mm}$. Meanwhile, the central hole is charged with a small amount of explosive, the cutting hole is charged continuously, and the peripheral hole is charged with air space. The blasting effect is shown in Figure 10.

The excavation footage is $1.8 \mathrm{~m}$ after blasting, which is a bit lower than that of straight parallel hole cutting. And the smooth effect is common. At the same time, the throwing distance is far and the size of rock slag is improved compared with straight parallel hole cutting.

5.3. Blasting Using the Double-Wedge Cutting. The cutting angles of double-wedge-shaped cutting are $80^{\circ}$, and the spacing between the first-level cutting holes is $250 \mathrm{~mm}$ and for the second-level cutting holes is $200 \mathrm{~mm}$. The central hole is not charged, the cutting holes are charged continuously, and the peripheral holes are charged segmentally. The blasting effect is shown in Figure 11. 


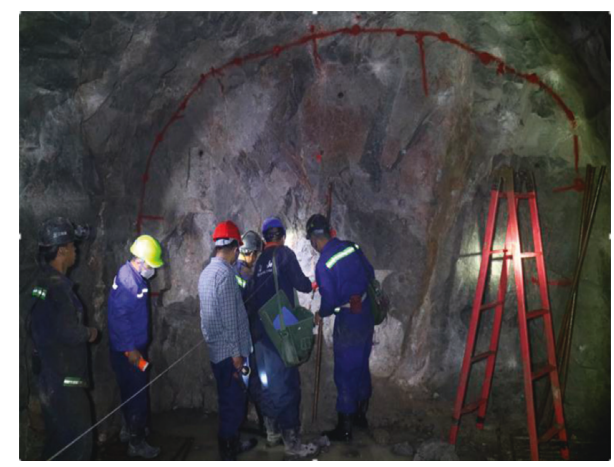

Figure 6: Preparation process of the blasting test.

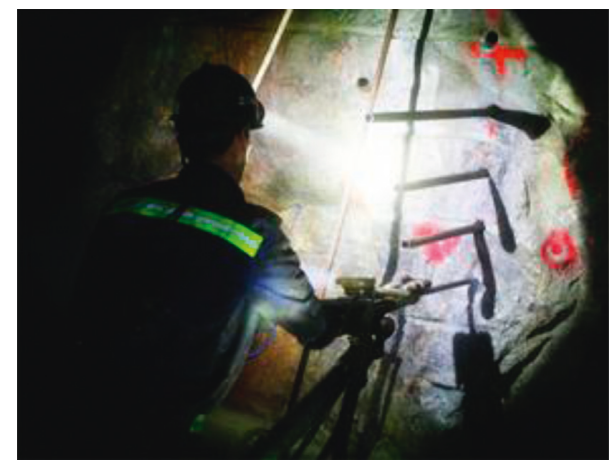

FIGURE 7: Drilling construction using the air pressure gun.

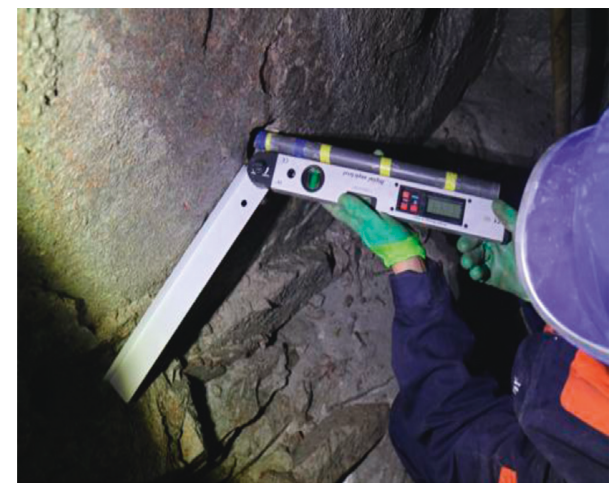

FIGURE 8: Geometric measurement of the drilling hole using a graduated stick.

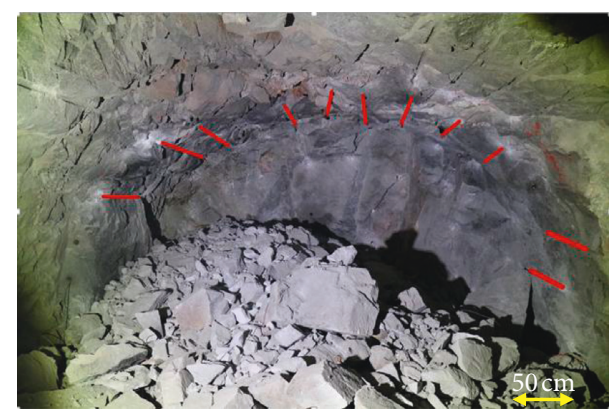

FIGURE 9: Blasting effect of straight parallel hole cutting.

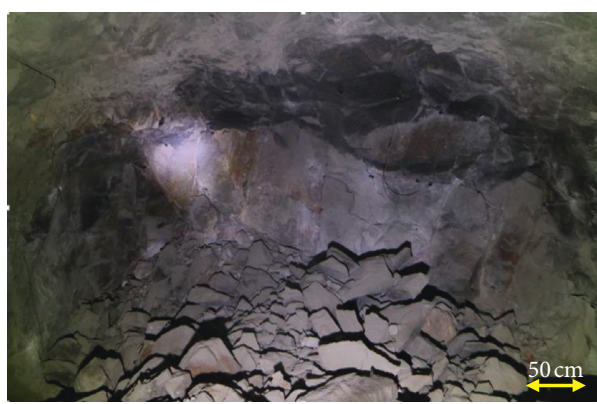

Figure 10: Blasting effect of single-wedge cutting.

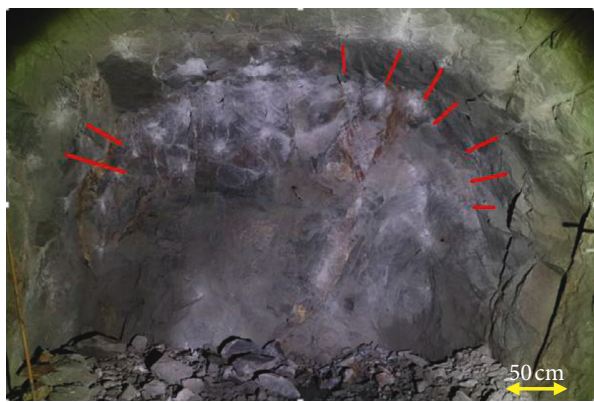

FIgURE 11: Blasting effect of double-wedge cutting.

After blasting, the footage of driving is $1.9 \mathrm{~m}$ and the ratio of half-hole and hole utilization is better. The slag throwing distance is proper, and the size of slag is suitable and uniform. In general, the double-wedge cutting blasting is more successful.

5.4. Testing Results. In the BET blasting site, according to the actual rock engineering geological conditions, the smooth blasting effects under different cutting parameters are verified. The blasting effect can be judged by parameters such as overexcavation and underexcavation, half-hole ratio of peripheral hole, and utilization ratio of blasting hole.

From the above descriptions, it can be seen that all the three cutting methods can achieve a better utilization ratio of blasting holes, and the excavation footage is $1.9 \mathrm{~m}, 1.8 \mathrm{~m}$, and $1.9 \mathrm{~m}$ respectively, all of which exceeds $90 \%$. According to the smooth blasting effect, the half-hole ratio of the peripheral hole is higher when the straight parallel hole cutting method is used, but it is general for that of the single-wedge cutting and the double-wedge cutting. From the point of the blasting slag pile distribution, the throwing distance of single-wedge cutting and double-wedge cutting is far, especially the single-wedge cutting, while the rock slag throwing distance is limited for the straight parallel hole cutting. Considering the homogenization degree of rock slag after blasting, the sizes of rock slag under the single-wedge and double-wedge cutting are more homogeneous.

Furthermore, the main reason of the above phenomena is the difference of the cutting method. According to the blasting principle, the resistance line of the straight parallel hole cutting is at the same distance away from the first-level auxiliary hole, but the resistance line of the single-wedge 
cutting and the double-wedge cutting is not the same. Therefore, the straight parallel hole cutting can achieve a good smooth effect under the condition of the same detonator initiation. Moreover, whether single-wedge or double-wedge cutting, compared with straight parallel hole cutting, the blasting face is broader, the role of rock clamping is smaller, resulting in the further throwing distance of the slag. Additionally, compared with the single-wedge cutting, the double-wedge cutting can break the rock more easily after the first-level cutting hole blasting. Meanwhile, the free surface produced by the first-level cutting also provides a better free volume for the second-level cutting, which is not only beneficial to the cutting, but also to the rock breaking. Therefore, it is very important to select and design a reasonable cutting method.

\section{Blasting Energy Analysis and Discussion}

Furthermore, the blasting effects of three different cutting methods are analyzed from the angle of blasting vibration and blasting energy attenuation.

The accurate characterization of each blasting parameter can be realized by the blasting vibration monitoring, and then the blasting parameters can be optimized.

6.1. Blasting Vibration Velocity Monitoring. According to the previous data analysis, it is considered that the blasting vibration speed at the top of the roadway is the largest, and that the top vibration resistance of the roadway is the worst. Therefore, there are three blasting vibration velocity sensors arranged on the top of the roadway, and the sensor is arranged at the side wall of the roadway at the same position, in which, three direction (radial, vertical, and tangent) sensors are placed at each measuring point. The base is fixed on the rock surface by lime powder coupling.

The first measuring sensor point is arranged $10 \mathrm{~m}$ away from the blasting face, and the other sensors are arranged at intervals of $5 \mathrm{~m}$. That is, three sets of sensors and six measuring points are linearly arranged along the top and side of the roadway from the blasting face, as shown in Figure 12.

The damage of blasting vibration to surrounding rock is different due to the difference of each charging parameter, cutting way, and geological condition.

Therefore, the measuring points of blasting vibration are closely followed after each blasting cycle, and the distance between the sensors and the blasting face and the sensors of each measuring point are consistent with the former blasting cycle. With this, the same objective condition of test data could be ensured and each blasting vibration value is more comparable.

Meanwhile, the instrument needs to be pretested carefully before every blasting vibration test, and the blasting vibration test procedure is referred to the blasting vibration detection instruction.

6.2. Blasting Vibration Velocity Analysis. Then, the blasting vibration has been monitored. Referring to the safety allowable standard of blasting vibration velocity of various structures in "Blasting Safety Regulations" (GB6722-2015), the reasonable range of the vibration velocity should be limited under $30 \mathrm{~cm} /$ s. And, the peak values of vibration velocity are $4.4 \mathrm{~cm} / \mathrm{s}$, $41.06 \mathrm{~cm} / \mathrm{s}$, and $16.27 \mathrm{~cm} / \mathrm{s}$ separately corresponding to the straight parallel hole cutting, single-wedge cutting, and double-wedge cutting. In which, the peak value of the singlewedge cutting exceeds the reasonable range.

The blasting vibration velocity corresponding to each blasting modes is inconsistent, which is mainly due to the different cutting ways. Among them, the first cutting way is straight parallel hole cutting, the second is the single-wedge cutting, and the third is the double-wedge cutting.

First of all, the peak value of vibration velocity caused by single-wedge cutting is oversized. Because the blasting effect is smooth, it shows that the cutting method and blasting parameters designed may be reasonable. However, the vibration velocity is too high, which indicates that it may not be enough to measure the impact of blasting vibration on facilities only using the peak vibration velocity.

At the same time, previous blasting tests have found that the peak blasting velocity of some observation points has exceeded the prescribed value of the Regulations [13-18], and a few of them even exceeded the upper limit value of the allowable vibration velocity of the mine roadway, for which the value is $30 \mathrm{~cm} / \mathrm{s}$. In fact, there exist no obvious cracks on the observed positions. It is shown that the frequency has a certain influence on the blasting vibration intensity.

The main frequency of straight parallel hole cutting is $35 \mathrm{~Hz}$, while the main frequency of single-wedge cutting is $55 \mathrm{~Hz}$. The increase of the main frequency indicates that the influence of blasting vibration on the free frequency of the facility is reduced. Therefore, even if the peak value of vibration velocity is increased, the smooth effect is still good, the half-hole ratio of surrounding rock is high, and the vibration of surrounding rock is also effectively controlled.

Compared with the peak value of vibration velocity between the straight parallel cutting and double-wedge cutting, the maximum vibration velocity increased from $4.4 \mathrm{~cm} / \mathrm{s}$ to $16.27 \mathrm{~cm} / \mathrm{s}$. However, the main frequency increased significantly from $35 \mathrm{~Hz}$ to $150 \mathrm{~Hz}$. The peak value of vibration velocity is still in a controllable range, and the main frequency increases obviously, which indicates that the double-wedge cutting optimizes the blasting effect and the BET vibration effect has been reduced.

6.3. Blasting Energy Analysis. Furthermore, it is shown that the energy distribution of blasting vibration corresponding to different cutting methods is also inconsistent. The distribution of vibration energy is shown in Figure 13.

It can be seen that the main frequency of vibration is lower for straight parallel cutting and the energy distribution in the high-frequency range is of normal distribution, which means the energy varies greatly. For doublewedge cutting, the energy distribution is basically uniform and the vibration energy distribution is approximately 


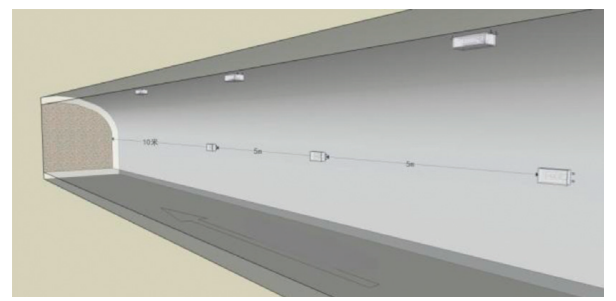

FigURE 12: Roadway roof and side wall blasting vibration observation point layout diagram.

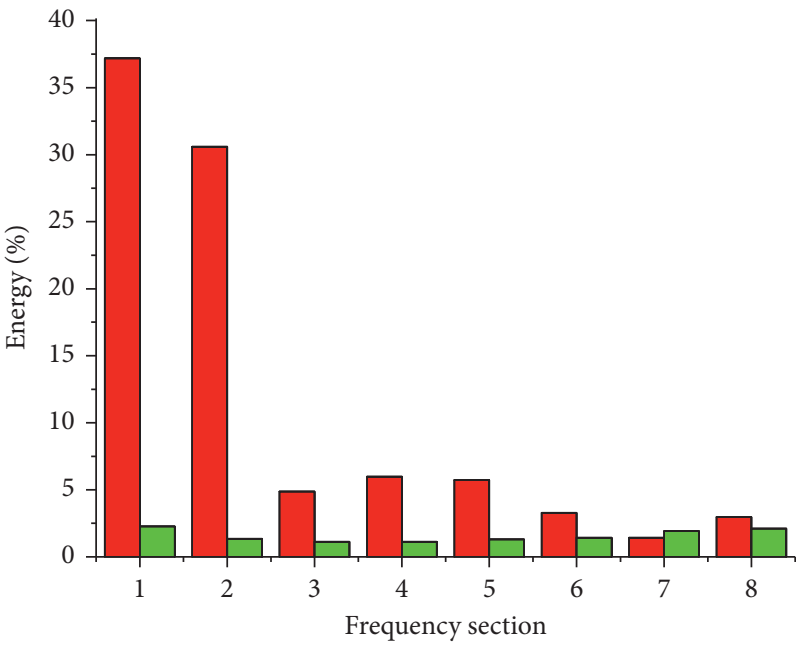

Parallel hole cutting

Double-wedge cutting

(a)

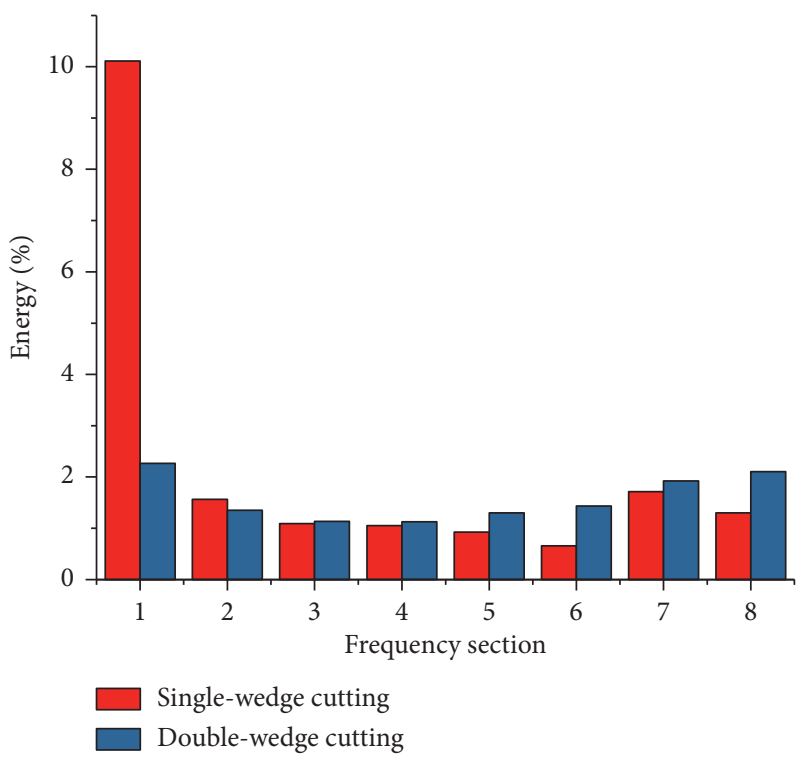

(c)

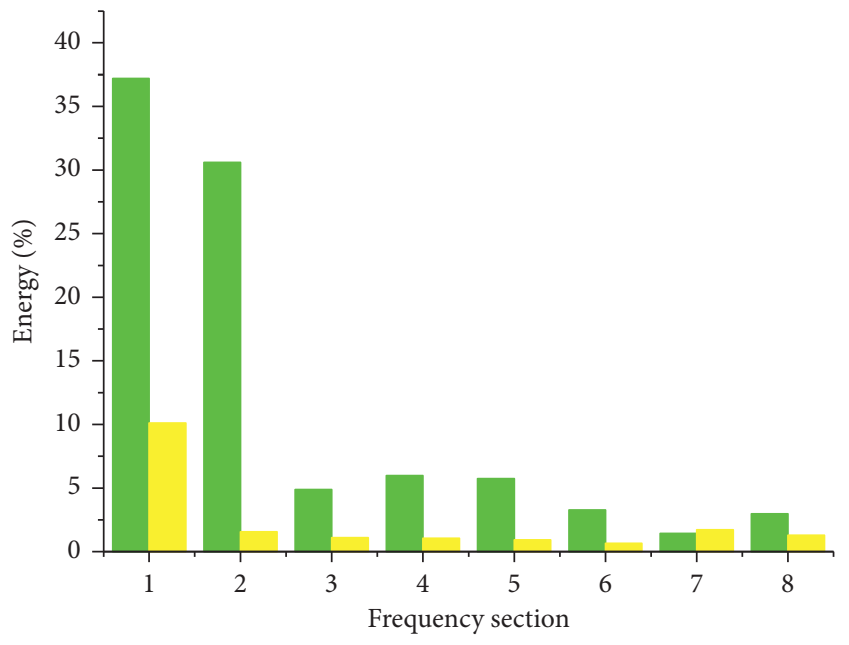

Parallel hole cutting

Single-wedge cutting

(b)

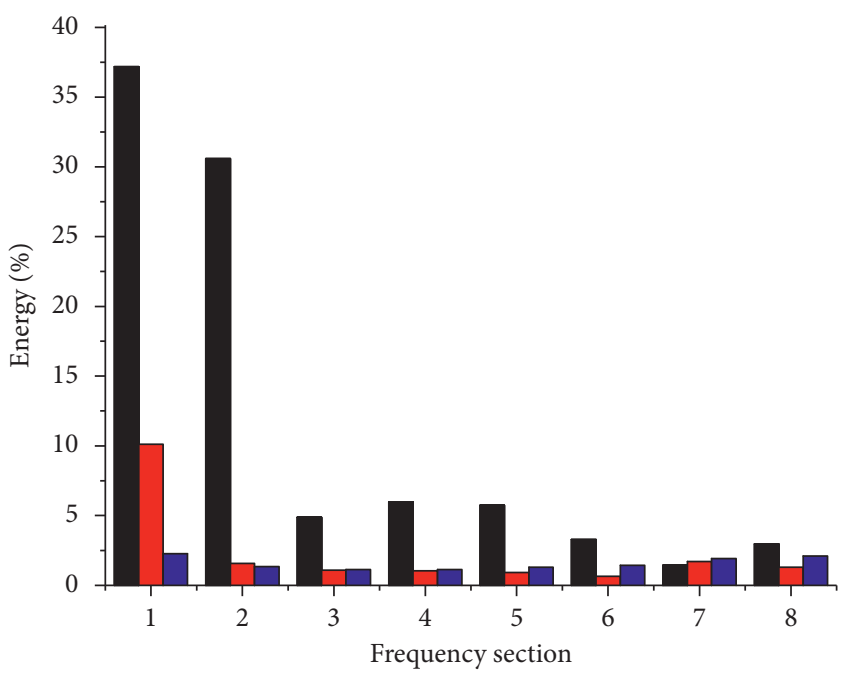

Parallel hole cutting

Single-wedge cutting

Double-wedge cutting

(d)

FiguRE 13: Energy percent distribution diagram of the cutting method during $250 \mathrm{~Hz}(1: 0-31.25 \mathrm{~Hz}, 2: 31.25-62.5 \mathrm{~Hz}, 3: 62.5-93.75 \mathrm{~Hz}, 4$ : 93.75-125 Hz, 5: $125-156.25 \mathrm{~Hz}, 6: 156.25-187.5 \mathrm{~Hz}, 7: 187.5-218.75 \mathrm{~Hz}, 8: 218.75-250 \mathrm{~Hz})$.

equivalent in each frequency band. Especially in the highfrequency band, it appears that the energy in the low frequency has migrated to the high frequency. This characteristic is much more advantageous to the stability of the building and is more conducive to the implementation of engineering blasting. 
It is found that the explosive energy distribution of straight parallel hole cutting is larger than that of wedge cutting.

The frequency of the $250 \mathrm{~Hz}$ range is divided into $8 \mathrm{sub}$ bands by the $31.25 \mathrm{~Hz}$ interval, and then, the variation trend of each sub-band's energy percentage under two different cutting ways is revealed.

As it can be seen from Figure 13, all the three cutting modes' energy are mainly concentrated in the vicinity of the main frequency band, and the energy distribution of other frequency bands is small.

The main frequency of blasting vibration for straight parallel hole cutting is low and the main frequency band range is narrow and small, especially the ratio of lowfrequency energy in the signal is larger.

The main frequency of double-wedge cutting is lower, and the frequency band range is wider. Meanwhile, the lowfrequency energy ratio in the signal decreases, and the energy distribution is obviously uniform.

The energy percentage in the straight parallel hole cutting is decaying exponentially, while the energy percentage of the double-wedge cutting takes on a steady trend. The energy percentage of the straight parallel hole cutting in the low-frequency section (below $62.5 \mathrm{~Hz}$ ) is much higher than that of the wedge-shaped cutting.

When the frequency band is in the range of 62.5$187.5 \mathrm{~Hz}$, the change of the energy percentage of the straight parallel hole cutting conforms to a normal distribution. However, the energy ratio of the double-wedge cutting is much more uniform, and there is no larger fluctuation.

In the range of high frequency $(187.5-250 \mathrm{~Hz})$, the energy percentage of the double-wedge cutting has a rising trend. It shows that the double-wedge cutting has a distinct frequency shift phenomenon compared with the straight parallel cutting way, which can transfer the energy percentage from a low frequency to a high frequency.

The energy distribution difference of explosive leads to the cross-section shape of the slot cavity after blasting. A narrow and long slot cavity can be formed by the wedgeshaped cutting, while a circular cavity could be occurred by the straight parallel hole cutting.

A long strip of stress concentration area is formed at the bottom of the blasting hole with the wedge-shaped cutting, and the rock mass can be fully broken in this range. However, as the distance increases from the cutting center to the blasting free face, the stress attenuation is aggravated and the breaking capacity for the rock decreases.

Comparing the straight parallel hole cutting and the wedge-shaped cutting, the straight hole cutting can get a much bigger slot cavity than the wedge-shaped cutting, while the double-wedge cutting is better than the straight hole cutting and the single-wedge cutting from the point of the rock breaking and ejection.

Therefore, when the straight parallel hole cutting is applied, the half-hole rate of the chamber is high and the slot cavity area range influenced by blasting is larger. And, it also leads to a smaller blasting vibration velocity caused by the explosive blasting on the rock.

However, for the double-wedge cutting, the explosive energy has not been fully affected by the explosive stress, especially at the edge of the cutting cavity. Thus, the blasting energy had to be absorbed much higher by the surrounding rock. Therefore, the blasting vibration velocities of the double-wedge cutting are higher than those of straight parallel hole cutting.

It also shows that besides the explosive charge quantity, the blasting vibration velocity is much more affected by the cutting way among many different kinds of influence factors.

\section{Conclusions}

(1) Based on the smooth blasting method, the blasting parameters of the Beishan exploration tunnel have been designed, which is much more suitable to this project. Furthermore, the smooth blasting influenced by the cave cutting method has been researched in detail. Three different cutting methods have been designed, i.e., straight parallel hole cutting, single-wedge cutting, and double-wedge cutting, for the same rock mass and geological condition with the same detonator sections and explosive quantity.

(2) In advance, the blasting has been carried out under the designed cutting methods. It is found that the straight parallel hole cutting has shown a better smooth effect, while the single-wedge and doublewedge cutting has indicated that the size of the rock fragment is almost even and the throw distance of the rock slag is a bit suitable.

(3) Moreover, the blasting vibration velocity and blasting energy have been analyzed. It is found that the energy distribution of single-wedge and doublewedge cutting is more uniform, mainly concentrated in the high-frequency part, while the energy of straight parallel hole cutting is more concentrated in the low-frequency part. Except the explosive quantity, the blasting vibration effect is also prone to be influenced by the cutting method.

As we known, the drilling and blasting method covers many different blasting parameters, and they influence each other. It should be pointed out that the data obtained from the blasting test in this paper are an exploration on different cutting methods and they are limited for the granite in the BET facility. This study can provide the corresponding experimental data and theoretical support for the subsequent excavation projects, and the result could be applied to the blasting and excavation of the deep geo-engineering and the HLW geo-disposal.

\section{Data Availability}

The data used to support the findings of this study are available from the corresponding author upon request.

\section{Conflicts of Interest}

The authors wish to confirm that there are no known conflicts of interest associated with this publication and 
there has been no significant financial support for this work that could have influenced its outcome.

\section{Acknowledgments}

This work was supported by the National Natural Science Foundation of China (grant no. 41202207). The authors are most grateful to Professor Yue Z. W. and Doctor Xu P. in China University of Mining and Technology, Beijing, for the valuable help with the tests.

\section{References}

[1] Y. Yang, Technology and Safety of Blasting in Mine, China Coal Industry Publishing House, Beijing, China, 1991.

[2] W. Wang, Drilling and Blasting, China Coal Industry Publishing House, Beijing, China, 1984.

[3] Y. Gu, X. Li, Y. Du et al., "Reasonable smooth blasting factor used in tunnel," Journal of Chongqing University: Natural Science, vol. 28, no. 3, pp. 95-97, 2005.

[4] J. Dai and Y. Yang, "Analysis of controlled perimeter blasting in damaged rock," Journal of University of Mining and Technology, vol. 29, no. 5, pp. 496-499, 2000.

[5] Y. Fu, X. Li, and L. Dong, "Analysis of smooth blasting parameters for tunnels in deep damaged rock mass," Rock and Soil Mechanics, vol. 31, no. 5, pp. 1420-1426, 2010.

[6] F. Dai, K. Xia, and L. Tang, "Rate dependence of the flexural tensile strength of Laurentian granite," International Journal of Rock Mechanics and Mining Sciences, vol. 47, no. 3, pp. 469-475, 2010.

[7] R. Shan, B. Huang, and W. Gao, "Case study on new technology application of quasi-parallel cut blasting in rock roadway drivage," Chinese Journal of Rock Mechanics and Engineering, vol. 30, no. 2, pp. 225-232, 2011.

[8] X. Wang, R. Shan, and B. Huang, "Application research on smooth blasting for cracked soft rock tunnelling," Blasting, vol. 25, no. 3, pp. 12-16, 2008.

[9] G. Yang, L. Jiang, and R. Yang, "Investigation of cut blasting with duplex wedge deep holes," Journal of China University of Mining and Technology, vol. 42, no. 5, pp. 755-760, 2013.

[10] W. Wang, C. Wu, and J. Li, "Numerical simulation of hybrid FRP-concrete-steel double-skin tubular columns under closerange blast loading," Journal of Composites for Construction, vol. 22, no. 5, article 04018036, 2018.

[11] Y. Lei, C. Zhou, and X. Rao, "Practice on improvement of blasting efficiency in drift excavation with reasonable cut method and blasting parameter," Engineering Blasting, vol. 12, no. 1, pp. 71-76, 2006.

[12] S. Chen, W. Haixia, and A. Xue, "Testing study on middle deep cut hole blasting in hard rock tunnel," Chinese Journal of Rock Mechanics and Engineering, vol. 26, no. 1, pp. 3498-3502, 2007.

[13] C. González-Nicieza, M. I. Álvarez-Fernandez, A. E. Alvarezvigil et al., "Influence of depth and geological structure on the transmission of blast vibrations," Bulletin of Engineering Geology and the Environment, vol. 73, no. 4, pp. 1211-1223, 2014.

[14] D. W. Lee and S. H. Kim, "An analysis of the results of trial blasting of site development project in the volcanic island," International Science Index, Civil and Environmental Engineering, vol. 10, no. 12, pp. 1534-1539, 2016.
[15] Y. Sun, Q. M. Li, S. A. McDonald, and P. J. Withers, "Determination of the constitutive relation and critical condition for the shock compression of cellular solids," Mechanics of Materials, vol. 99, pp. 26-36, 2016.

[16] J. Chen, X. Li, and J. Zhang, "Study on blasting parameters of protective layer excavation of rock bench based on blasting induced damage," Chinese Journal of Rock Mechanics and Engineering, vol. 35, no. 1, pp. 98-108, 2016.

[17] R. Yang, C. Ding, L. Yang, and Y. Wang, "Experimental study on controlled directional blasting on PMMA mediums with flaws," Chinese Journal of Rock Mechanics and Engineering, vol. 36, no. 3, pp. 690-696, 2017.

[18] H. Li, X. Li, J. Li, X. Xia, and X. Wang, "Application of coupled analysis methods for prediction of blast-induced dominant vibration frequency," Earthquake Engineering and Engineering Vibration, vol. 15, no. 1, pp. 153-162, 2016. 


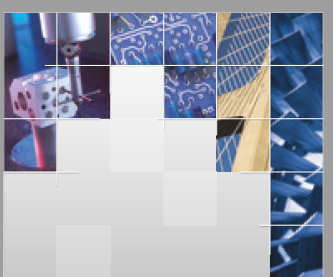

\section{Enfincering}
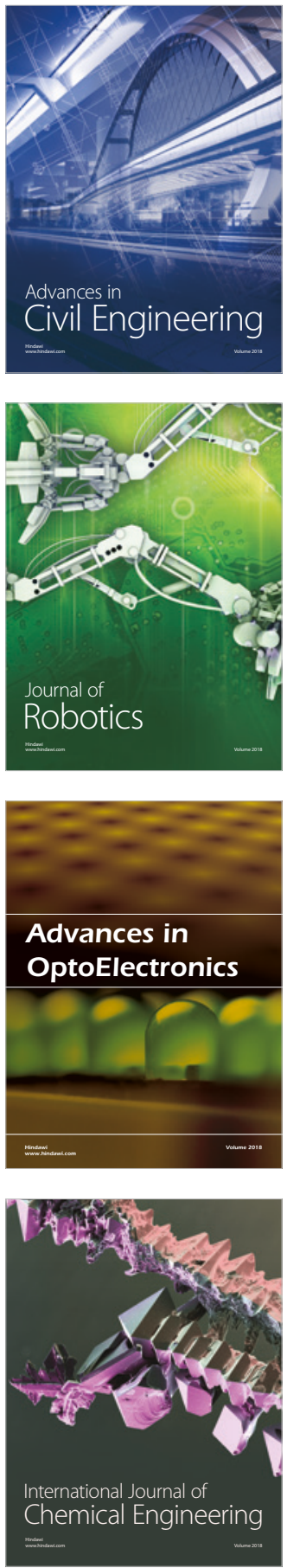

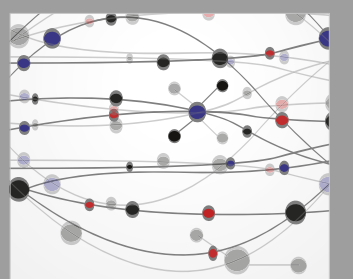

\section{Rotating \\ Machinery}

The Scientific World Journal

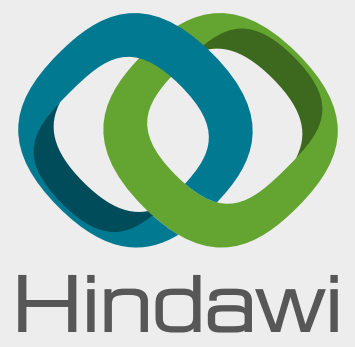

Submit your manuscripts at

www.hindawi.com
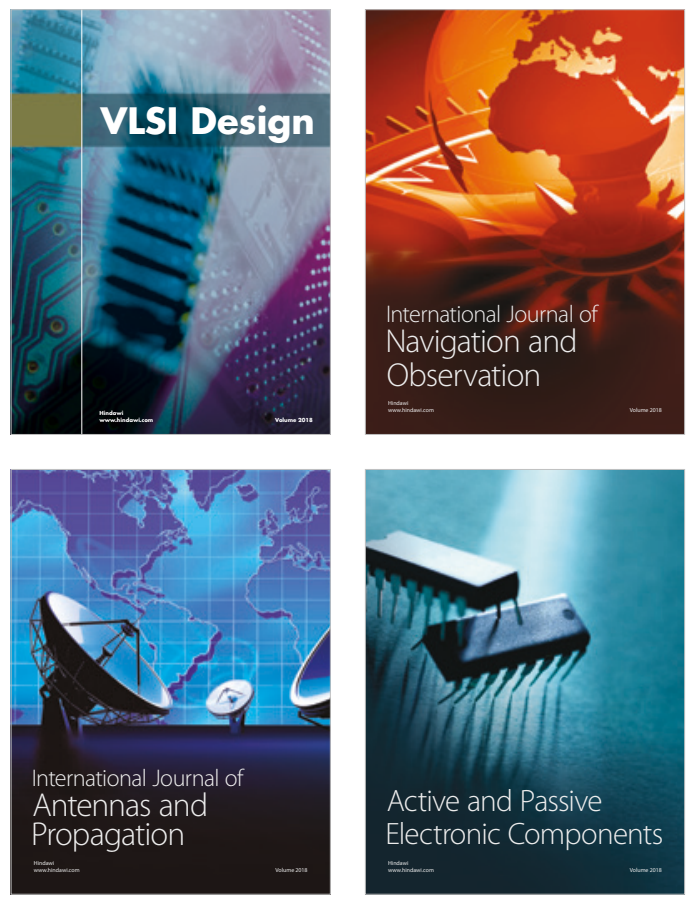
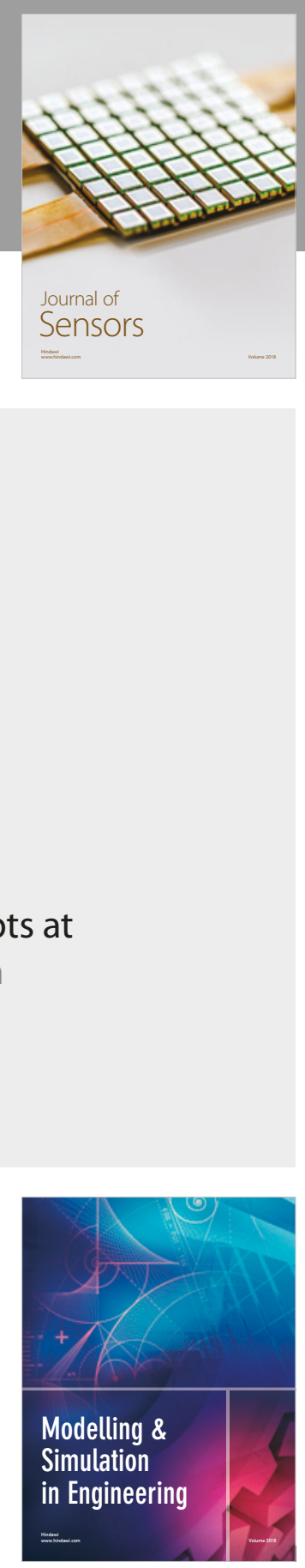

\section{Advances \\ Multimedia}
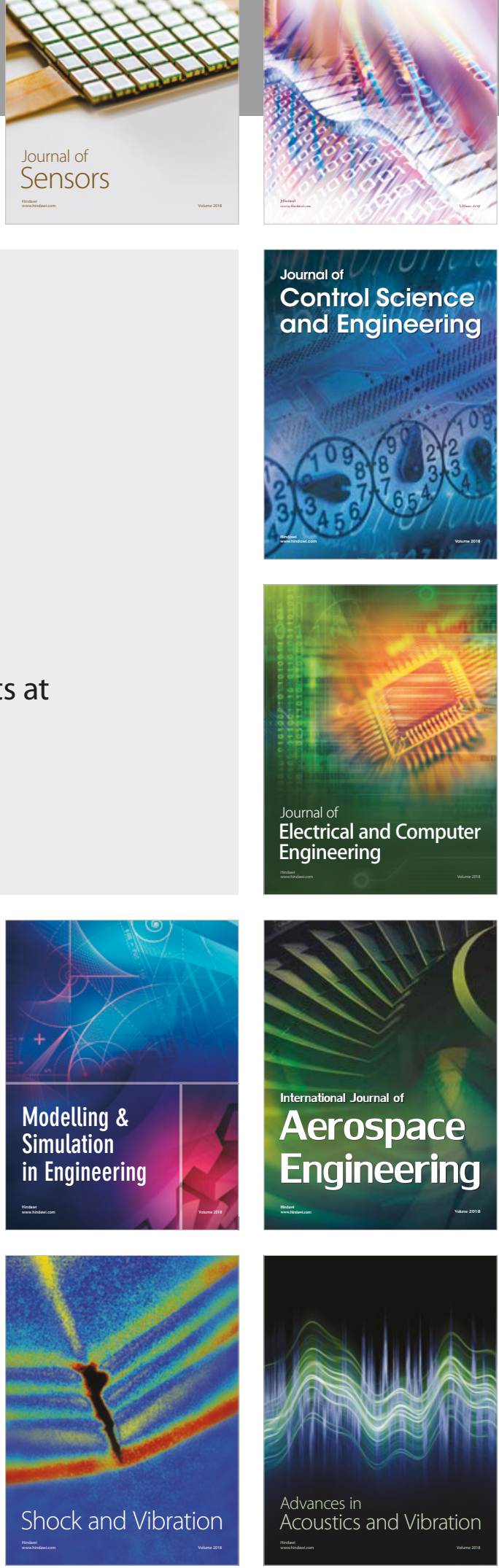